\title{
BIBLIOGRAFÍA DE Ma JESÚS RUBIERA MATA
}

1966

1. "El significado del nombre de los Banū Ašqilūla", Al-Andalus 31 (1966), pp. 377-378.

1967

2. "Tres topónimos de la frontera granadina", Al-Andalus 32 (1967), pp. 217-220.

1969

3. "El D̄ū l-wizāratayn Ibn al-Hakīm de Ronda", Al-Andalus 34 (1969), pp. 105-121.

1970

4. "Datos sobre una «madrasa” en Málaga anterior a la nașrī de Granada", Al-Andalus 35 (1970), pp. 223-225.

5. "Los poemas epigráficos de Ibn al-Ŷyayyāb en la Alhambra", $A l$ Andalus 35 (1970), pp. 453-473.

1972

6. "De nuevo sobre las tres morillas", Al-Andalus 37 (1972), pp. 133-143.

1973

7. "Sur un possible auteur de la chronique intitulée "al-Hulal almawšiyya fĩ dikr al-ajbār al-Marrākưiyya", II Coloquio Hispano-Tunecino, Madrid, 1973, pp. 143-146. 
1974

8. "La poesía cinegética árabe", Orientalia Hispanica sive studia F. $M^{a}$ Pareja dedicavit, Leiden, 1974, pp. 566-579.

1975

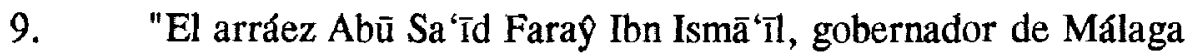
y epónimo de la segunda dinastía nașri de Granada", Boletin de la Asociación Espafola de Orientalistas 11 (1975), pp. 127133.

1976

10. "De nuevo sobre los poemas epigráficos de la Alhambra", AlAndalus 41 (1976), pp. 207-211.

11. "Ibn Zamrak, su biógrafo Ibn al-Ahmar y los poemas epigráficos de la Alhambra", Al-Andalus 42 (1977), pp. 447-451.

1978

12. "Un aspecto de las relaciones entre la Ifrīqiya hafṣi y la Granada Nașrī: la presencia tunecina en las tariqāit místicas granadinas", Les Cahiers de Tunisie. Actes de la 3ème. Rencontre Tuniso-Espagnole, Universidad de Túnez, tomo 26, $n^{0} 103-104,1978$, pp. 165-172.

13. "El vínculo cognático en al-Andalus", Actas del I Congreso de Historia de Andalucia. Andalucia Medieval I, Córdoba, 1978, pp. 121-124.

1980

14. "Las décimas del profeta. (Mu'ašsarāt, 'išrīniyyāt, talātīniyyāt y mujammasāt: versos con epanadiplosis en la poeśa hispanoárabe)", Al-Qantara 1 (1980), pp. 55-64.

15. "La mesa de Salomón", Awrdq 3 (1980), pp. 55-64.

16. "Literatura hispano-árabe", en Historia de las literaturas hispánicas no castellanas (dir. José María Díez Borque), Ed. Taurus, Madrid, 1980, pp. 141-176. 
1981

17. "Los Banū Escallola, una dinastía granadina que no fue", Andalucla Islámica, Granada, 2 (1981-1982), pp. 85-94.

18. "Poesia epigráfica en la Alhambra y el Generalife", Poesia, Madrid, 13 (1981), pp. 17-76.

19. "La literatura arabigoandaluza", Historia de Andalucía V, Barcelona, 1981, pp. 42-79.

20. La arquitectura en la literatura arabe. Datos para una estetica del placer, Editora Nacional (Biblioteca de visionarios, heterodoxos y marginados), Madrid, 1981, $181 \mathrm{pp}$.

21. "Algunos problemas cronológicos en la biografia de $\mathrm{Al}-$ Mu'tamid de Sevilla: La conquista de Silves y el matrimonio con Rumaykiyya", Actas de las Jornadas de Cultura Árabe e Islámica (1978), Instituto Hispano-Árabe de Cultura, Madrid, 1981, pp. 231-245.

1982

22. "Literatos de Sharq Al-Andalus: Abū Șalt de Denia e Ibn Dihyà de Calpe", Revista del Instituto de Estudios Alicantinos, Alicante, 36 (1982), pp. 33-43.

23. Al-Mu'tamid Ibn 'Abbad. Poestas. Antologta bilingüe, Instituto Hispano-Árabe de Cultura, 3, Madrid, 1982, 129 pp.

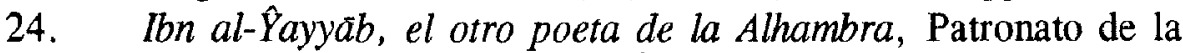
Alhambra / Instituto Hispano Árabe de Cultura, Granada, 1982, $187 \mathrm{pp}$.

25. "Significado de algunos topónimos árabes de Aspe", La Serranica, Aspe, 36 (1982), pp. 17-18.

26. "El poeta Ibn al-Labbāna en Mallorca", Butllett de la Societat Arqueoldgica Lul.liana, Palma de Mallorca, 39 (1983), pp. 503-509.

27. "Elias Terés (1915-1983)", Awraq, Madrid, 5-6 (1982-1983), pp. 302-303.

28. "Antigua literatura arabe" en Historia universal de la literatura, Orbis, 48, Barcelona, 1983, 17 pp. 
29. "Elda en el Pacto de Tudmir: camino y fortaleza", Alborada, Elda, vol. XXIX (1983), 1 p.

30. "Aspe, la gran calzada y el camino de la Almohaja", La Serranica, Aspe, 37 (1983), 2 pp.

31. "La descripción poética de los palacios árabes: datos para la definición del género "Qușūriyyāt"", Actas del IV Coloquio Hispano-Tunecino (Palma de Mallorca, 1979), Instituto Hispano-Árabe de Cultura, Madrid, 1983, pp. 213-215.

32. "Álava y los alaveses en los textos árabes medievales", Congreso de Estudios Históricos "La Formación de Álava. 650 Aniversario del Pacto de Arriaga (1332-1982)", Ponencias, Vitoria-Gasteiz, Diputación, 1984, pp. 385-393.

33. (con Míkel de Epalza) "El mosaico árabe de Petrel y la existencia de unos posibles baños árabes", Revista de Fiestas, Petrel, 1984, 1 p.

34. "Rafals y raales; ravals y arrabales; reals y reales", Sharq AlAndalus. Estudios Árabes, Universidad de Alicante, 1 (1984), pp. 117-122.

35. "Posible identificación del Ibn al-Royōlo de Denia, ministro de al-Muqtadir de Zaragoza (s. XI)", Sharq al-Andalus. Estudios Árabes, Alicante, 1 (1984), pp. 147-149.

36. "Precisiones sobre los dialectos arábigo-granadino y arábigo-valenciano", Sharq al-Andalus. Estudios Árabes, Universidad de Alicante, 1 (1984), pp. 151-152.

37. "Toponimia arábigo-valenciana: Falsos antropónimos beréberes", Miscel-lania Sanchis Guamer. Quaderns de Filologia, València, vol. I, 1984, pp. 317-320.

38. "La corte literaria de Sa'īd de Menorca (s. XIII)", Revista de Menorca, Mahón, 75 (1984), pp. 105-138.

39. Un benissero ilustre: el poeta árabe Ibn al-Labbāna, Benissa, Ayuntamiento de Benissa, 1984, 12 pp.

1985

40. "Madjrīt", Encyclopédie de l'Islam, Leiden-París, Ed. J. Brill, vol. V, 1985, pp. 95-96. 
41. "Una república musulmana en Xàtiva (siglo XI)", Xàtiva, Xàtiva, 1985, pp. 101-104.

42. "Muhammad Ben-Isa al-Labbana", Antologia de escritores benisseros, Benissa, 1985, pp. 11-18.

43. "Los omeyas. Arte y literatura", Cuadernos Historia 16, Madrid, Los Omeyas 25 (1985), pp. 19-24.

44. "Valencia en el Pacto de Tudmīr", Sharq Al-Andalus. Estudios Árabes, Alicante, 2 (1985), pp. 119-120.

45. Villena en las calzadas romana y árabe, Alicante, Ayuntamiento de Villena/Universidad de Alicante, $1985,62 \mathrm{pp}$.

46. La Taifa de Denia, Alicante, Instituto "Juan Gil Albert", Diputación Provincial de Alicante, 1985, 172 pp.

47. (con Míkel de Epalza) Los nombres arabes de Benidorm y su Comarca, Alicante, Ayuntamiento de Benidorm/Universidad de Alicante, 1985, $65 \mathrm{pp}$.

48. (con Míkel de Epalza) Els noms arabs de Benidorm i la seua comarca, Alacant, Ajuntament de Benidorm/Universitat d'Alacant, 1985, $65 \mathrm{pp}$.

49. "Rasgos mediterráneos de la poesía de Al-Andalus", 2on Encontre d'Escriptors del Mediterrani "Literatura i Societat", València, Ajuntament de Valencia, 1985, pp. 198-201.

1986

50. (con Míkel de Epalza) "La sofra (sujra) en el Sharq Al-Andalus antes de la conquista catalano-aragonesa", Sharq Al-Andalus. Estudios Árabes, Alicante, 3 (1986), pp. 33-37.

51. "El vocablo árabe «sikka» en su acepción de vía y de sus posibles arabismos en la toponimia hispánica: Aceca, Seca y Villa Seca", Sharq Al-Andalus. Estudios Árabes, Alicante, 3 (1986), pp. 129-132.

52. "Estructura de "Cantar de Gesta" en uno de los relatos de la conquista de Al-Andalus", Revista del Instituto Egipcio de Estudios Istamicos en Madrid, Madrid, 23 (1985-1986), pp. 64-78.

53. (con Míkel de Epalza) "Los cristianos toledanos bajo dominación musulmana", Simposio Toledo Hispanoárabe, 6-8 de mayo 
de 1982, Toledo, Colegio Universitario de Toledo, 1986, pp. 129-133.

54. (con Míkel de Epalza) "Estat actual dels estudis de toponímia valenciana d'origen àrab", X Col-loqui General de la Societat d'Onomàstica, 1986, Valencia, 1986, pp. 420-426.

1987

55. "La lengua romance de las jarchas (una jarcha en lengua occitana)", Al-Qantara, Madrid, 8 (1987), pp. 319-329.

56. "La Rápita de Benissa", Mil·lenari de Benissa, Benissa, 1987, $3 \mathrm{pp}$.

57. (con Míkel de Epalza) "El mosaico romano de Petrer y la existencia de unos posibles baños árabes", Páginas de nuestra historia, Petrer, 1987, p. 7.

58. Al-Mu'tamid lbn 'Abbad. Poesias. Antologia bilinglie, Instituto Hispano-Árabe de Cultura, Madrid, 1987, $2^{\mathrm{a}}$ edición, $129 \mathrm{pp}$.

59. (con Míkel de Epalza) Xativa musulmana (segles VIII-XIII), Ajuntament de Xàtiva, Xàtiva, 1987, 202 pp.

60. "Los estudios de toponimia hispano-árabe a la luz de dos publicaciones recientes: Materiales para el estudio de la toponimia hispano-arabe: Nómina Fluvial de Elras Terés y La división territorial de la España musulmana de Joaquín Vallvé", Sharq al-Andalus. Estudios Árabes, Alicante, 4 (1987), pp. 365-366.

61. "El príncipe hastiado, Muhammad Ibn 'Abdalmalik Ibn Abī "Āmir, efímero soberano de Orihuela y Murcia", Sharq AlAndalus. Estudios Árabes, Alicante, 4 (1987), pp. 73-81.

62. "Las incripciones árabes de Játiva: una hipótesis y una propuesta sobre la denominación de un estilo", Homenaje al Prof. Darto Cabanelas Rodrtguez, O.F.M., con motivo de su LXX Aniversario, Granada, Universidad de Granada, vol. II, 1987, pp. 293-295.

63. "Los precedentes geopolíticos musulmanes del señorío de Villena", Congreso de Historia del Señorio de Villena, Albacete 23-26 octubre 1986, Albacete, Instituto de Estudios Albacetenses / C.S.I.C., 1987, pp. 357-360. 
64. "La lengua árabe y la lengua valenciana", Las lenguas prevalencianas, Alicante, Universidad de Alicante, 1987, pp. 93-95.

65. "Versions de poesia aràbigo-valenciana: Ibn Khafaja d'Alzira (1058-1139)", Trenc d'Alba, Alacant, 2 (1988), pp. 21-22.

1988

66. "La funcion estética del agua en la civilización arabigoislámica", Agua y poblamiento musulman/Aigua i poblament musulmà, Benissa, Ajuntament de Benissa, 1988, pp. 11-12.

67. La taifa de Denia, Instituto "Juan Gil Albert", Alicante, Diputación Provincial de Alicante, $2^{\mathrm{a}}$ edición, 1988, $172 \mathrm{pp}$.

68. La arquitectura en la literatura árabe (segunda edición aumentada), Madrid, ed. Hiperión, 1988, 196 pp.

69. Bibliografia de la literatura hispano-árabe, Alicante, Universidad de Alicante, 1988, $75 \mathrm{pp}$.

70. "La conquesta de València per Jaume I com a tema literari en un testimoni de l'esdeveniment: Ibn Al-Abbār de València", L'Aiguadolc, Marina Alta, Inst. de Est. Juan Gil Albert / I.E.M.A., n. 7 (tardor 1988), pp. 33-44.

71. "El Baix Vinalopó durant l'època àrab", La Rella, Elx, Ajuntament d'Elx, 6 (1988), pp. 49-56.

72. "Nueva aproximación al estudio literario de las jarchas andalusfes", Sharq Al-Andalus. Estudios Árabes, Alicante, 5 (1988), pp. 89-100.

73. "El Dū 1-Wizāratayn Ibn Al-Hakīm de Ronda", Estudios sobre Ronda y su Serranía. $N^{\circ} .1$. V Centenario de la incorporación de Ronda a la Corona Castellana (1485-1985), Granada, Universidad de Granada, 1988, pp. 205-218.

74. "Lo árabe en la poesía de Sergio Macías", Prólogo a Sergio Macias: Tetuán en los suefios de un andino, Madrid, ed. Betania, 1989, pp. 13-15.

75. "La cultura musulmana: Pensament, Llenguatge i formes literàries (Aspectes de la poesia aràbigo-valenciana: el paradís i el paradís perdut)", En torno al 750 Aniversario. Antecedentes 
y consecuencias de la conquista de Valencia, València, Consell Valencià de Cultura de la Generalitat, 1989, pp. 98-106.

76. "Relacions d'anada $i$ tornada entre la poesia provençal i la poesia àrab a través dels catalans: Kharges en llengua occitana", Actes del Vuité Col-loqui Internacional de Llengua $i$ Literatura Catalanes, Montserrat, Publicacions de l'Abadia de Montserrat, vol. I, 1989, pp. 237-244.

77. "Oficios nobles, oficios viles", La mujer en Al-Andalus. Reflejos históricos de su actualidad y categortas sociales, Madrid-Sevilla, Universidad Autónoma / Editoras Andaluzas Reunidas, 1989, pp. 71-76.

78. "Cançonetes de tipus 'Kharja' en la literatura catalana", Miscel-lània Joan Fuster. Estudis de Llengua i Literatura, Barcelona, Publicacions de l'Abadia de Montserrat, vol. I, 1989, pp. $1-8$.

79. "Els toponims aràbigo-catalans del Baix Segura (Alacant)", Sharq Al-Andalus. Estudios Árabes, Alicante, 6 (1989), pp. 159-160.

80. Introducció a la Literatura Hispano-Àrab, Alacant, Universitat d'Alacant (Col-lecció Xarc Al-Andalus, 1), 1989, 117 pp.

81. "Un insólito caso de conversas musulmanas al cristianismo: las princesas toledanas del siglo XI", Las mujeres en el cristianismo medieval. Imágenes teóricas y cauces de actuación religiosa, Madrid, Asociación Cultural "Al-Mudayna", 1989, pp. 341-347.

1990

82. Poesta femenina hispanoârabe, Madrid, ed. Castalia / Instituto de la Mujer, 1990, $163 \mathrm{pp}$.

83. L'immaginario e l'architettura nella letteratura araba medievale (traducción de La arquitectura en la literatura arabe), edición y prólogo de Ennio Concina, Génova, ed. Marietti, 1990, 158 pp.

84. "El món cavalleresc àrab i el món cavalleresc del Tirant", Afers, Catarroja (Valencia), 10 (1990), pp. 267-274.

85. "Una fórmula elocutiva en la lírica tradicional romànica i una altra possible khartja occitana", A Sol Post. Estudis de Llengua 
i Literatura, Alcoi, ed. Marfil, Col·leccio "Universitas", no 1 (1990), pp. 193-196.

86. "La toponimia árabe de Madrid", Madrid del siglo IX al XI, Madrid, Consejería de Cultura de la Comunidad de Madrid, 1990, pp. 165-170.

87. "Ibn Al-Abbār i el seu temps", Ibn al-Abbār. Polltic i escriptor arab valencia (1199-1260), Valencia, Conselleria d'Educació i Ciència, Generalitat Valenciana, 1990, pp. 13-18.

88. "Una nueva hipótesis sobre la lengua de las jarchas a partir de las investigaciones de Rafael Lapesa", Homenaje al Profesor Lapesa, Murcia, Universidad de Murcia, 1990, pp. 227-232.

89. "Tirant lo Blanc i els moros", L'Aiguadolc, La Marina Alta, 12-13, tardor 1990, pp. 33-40.

90. "Prólogo", Francisco Franco Sánchez - Marla Sol Cabello. Muhammad Aš-Šafra. El médico y su época, Alicante, Universidad de Alicante, 1990, pp. 13-15.

1991

91. "El "Tirant" i la literatura àrab", Serra d'Or, Montserrat, no 371 (1991), pp. 57-58.

92. "Tunisie dans une nouvelle du dramaturge espagnol Félix Lope de Vega", Revue d'Histoire Maghrébine, Zaghouan (Túnez), C.E.R.O.M.D.I., 63-64 (juillet, 1991), pp. 417-421.

93. "Dos cuentos árabes medievales en la literatura hispánica: «El viejo celoso» y «El aterrizaje sin cola»", Sharq Al-Andalus. Estudios Árabes, Alicante, 8 (1991), pp. 55-59.

94. "Els camins àrabs de la muntanya i la Marina alacantines i una hipòtesi sobre el nom d'Alcoi", Societat d'Onomastica. Butlletí Interior. XIVe. Col-loqui. Alacant, (13-15-IV-1989), València, Societat d'Onomàstica, 44 (març, 1991); Alacant, Publicacions de la Universitat d'Alacant, t. II, 1991, pp. 671-672.

95. "Introducción a la nueva edición" Jaime Oliver Asín, Historia del nombre de Madrid, Madrid, Instituto de Cooperación con el Mundo Árabe, 1991, pp. I-XVI.

96. "Presencia románica extra-andalusí en las jarchas", Actas del Primer Congreso Internacional sobre Poesía Estrofica Árabe y Hebrea y sus Paralelos Romances (Madrid, diciembre de 
1989), Madrid, Facultad de Filologra, Universidad Complutense, Instituto de Cooperación con el Mundo Árabe, 1991, pp. 289-295.

97. "Arquetipos ideales de la ciudad árabe", Simposio Internacional sobre la Ciudad Islámica, Ponencias y comunicaciones, Zaragoza, Institución "Fernando el Cat6́lico", 1991, pp. 57-64.

98. "Tirant lo Blanc $\mathrm{i}$ els moros", Moros y Cristianos, Novelda, Ayuntamiento de Novelda, 1991, pp. 25-30.

99. "Presentación", Manuel Espinar Moreno. Vivo la Alhambra. El Agua, Granada, Proyecto Sur de Ediciones, 1991, pp. 3-4.

100. "Les premiers Mores convertis ou les prémises de la tolérance", Tolede XIT-XIIT. Musulmans, chrétiens et juifs: le savoir et la tolérance (dir. Louis Cardaillac), Paris, éds. Autrement, 1991, pp. 102-111.

1992

101. Literatura Hispanoárabe, Madrid, ed. Mapfre, 1992, 283 pp.

102. "Los primeros moros conversos o el origen de la tolerancia", Toledo s. XII-XIII. Musulmanes, cristianos y judlos, Madrid, Alianza Editorial, 1992, pp. 109-117.

103. "La poesła epigráfica de los palacios de la Alhambra", Realidad y simbolo de Granada, Madrid, Banco Bilbao-Vizcaya, 1992, pp. 265-271.

104. "La expansión del Islam" Anuario de los temas 1992, Barcelona, Difusora Internacional, 1992, pp. 116-137.

105. "La voz de las poetisas en al-Andalus y la problemática de la voz femenina literaria medieval", La voz del silencio I: Fuentes directas para la historia de las mujeres (siglos VIII-XVII), (Cristina Segura Graíño, editora), Madrid, 1992, pp. 65-70.

106. "Joan Fuster y la poesfa árabe", Sharq al-Andalus. Estudios Árabes, Alicante, 9 (1992), pp. 89-92.

107. Ibn Muqana de Alcabideche, Cascais (Portugal), Al-Qabdaq. Boletim Cultural da Junta de Freguesia de Alcabideche - 1992, $35 \mathrm{pp}$.

108. "Toponímia àrabo-valenciana: falsos antropònims berbers", Miscel-lania Sanchis Guarner, Montserrat, Publicacions de l'Abadia de Montserrat, vol. III, 1992, pp. 157-166. 
109. "L'islam: àrabs i musulmans, Problemàtica actual de l'Islam", Alacant, ed. Asociació Universitària Joan Fuster, Universitat d'Alacant, 1993, pp. 7-22; 38-44.

110. Tirant contra el Islam, Altea (Alicante), Ediciones Aitana, 1993, 93 pp.

111. "Una possible font àrab de l'estructura argumental de les Cobles de la divisió del Regne de Mallorca", Actes del Novè Col-loqui Internacional de Llengua i Literatura Catalanes, Alacant/Elx 9-14 de setembre de 1991, Montserrat, Publicacions de l'Abadia de Montserrat / Universitat d'Alacant / Universitat de València, vol. I, 1993, pp. 161-166.

112. "Els arabismes del català. Història d'un rebuig", Actes del Novè Col-loqui Internacional de Llengua i Literatura Catalanes, Alacant/Elx 9-14 de setembre de 1991, Montserrat, Publicacions de l'Abadia de Montserrat / Universitat d'Alacant / Universitat de València, vol. II, 1993, pp. 301-317.

113. "Jarchas de posible origen galaico-portugués", Literatura Medieval. Actas do IV Congresso da Associaçáo Hispanica de Literatura Medieval, Lisboa, Ediciones Cosmos, 1993, pp. 7981.

1994

114. Ibn al-Yayyab. El otro poeta de la Alhambra (2a edición), Granada, Patronato de la Alhambra y Generalife, 1994, 259 pp.

115. (dirección) Introducción a los estudios árabes $e$ islámicos, Alicante, Área de Estudios Árabes e Islámicos, Universidad de Alicante, 1994, $123 \mathrm{pp}$.

116. (direcció) Introducció als estudis arabs $i$ islamics, Alacant, Àrea d'Estudis Àrabs i Islàmics, Universitat d'Alacant, 1994, $131 \mathrm{pp}$.

117. "La dieta de Ibn Quzmān. Notas sobre la alimentación andalusí a través de su literatura", La alimentación en las culturas islamicas (Manuela Marín y David Waines editores), Madrid, Agencia Española de Cooperación Internacional, 1994, pp. 127136. 
118. "Els elements araboislàmics en el Tirant lo Blanc", L'Avenc, Barcelona, 181 (maig 1994), pp. 50-53.

119. "La ciudad como jardín y el jardín como ciudad: la Alhambra", Literatura y espacio urbano (José Carlos Rovira y José Ramón Navarro editores), Alicante, CAM, Fundación Cultural, 1994, pp. 175-185.

120. "Le module de la Cité Pétrifiée et sa présence dans la littérature hispanique", Les Mille et Une Nuits. Contes sans frontière (Edgar Weber editor), Toulouse, AMAM, 1994, pp. 221-227.

121. "Introducción" a Sergio MACÍAS, El manuscrito de los sueños, Santiago de Chile, Ediciones Zona Azul, 1994, pp. 9-12.

122. "Il giardino islamico come metafora del paradiso", $l l$ giardino Islamico. Architettura, natura, paesaggio, Milán, Ed. Electa, 1994, pp. 13-24. 